\title{
Barbed wire as an oesophageal foreign body in an Emu (Dromaius novaehollandiae)
}

\begin{abstract}
The clinical case report puts on record a rare case of barbed wire as an oesophageal foreign body in a 3 year old female Emu, weighing $40 \mathrm{~kg}$. The bird was anorexic from the last 2 weeks. The barbed wire could be palpated percutaneously. Radiographs were taken to confirm the nature of foreign body. Oesophagotomy of the bird was done under general anaesthesia using Inj. xylazine $2 \mathrm{mg} / \mathrm{kg}$ and inj. ketamine $10 \mathrm{mg} / \mathrm{kg}$ combination, intramuscularly, to retrieve the foreign body. The bird recovered partially from anesthesia but died after 24 hrs. it is concluded that such cases can be successfully surgically treated if presented early.
\end{abstract}

Keywords: avian, bird, foreign body, oesophagus, wire
Volume 4 Issue 3 - 2019

\section{Vandana Sangwan, Shashi Kant Mahajan, Ashwani Kumar, Arun Anand \\ Department of Veterinary Surgery and Radiology, Guru Angad Dev Veterinary and Animal sciences University, India}

\author{
Correspondence: Vandana Sangwan, Department of \\ Veterinary Surgery and Radiology, Guru Angad Dev Veterinary \\ and Animal sciences University, India, \\ Email drvandanasangwan@rediffmail.com
}

Received: April 30, 2019| Published: June 06, 2019

\section{Introduction}

Emu (Dromaius novaehollandiae) is a flightless and second largest living bird of the world. ${ }^{1}$ Emu's diet includes fruits, seeds, shoots of plants and insects. Emu does not have crop but the oesophageal mucous membrane is arranged in longitudinal folds to allow distension and swallowing of bulky food. Ingestion of metallic foreign body causing oesophageal obstruction is rare in birds. ${ }^{2,3}$ This case report describes oesophageal obstruction due to ingestion of a bunch of barbed wire in an Emu.

\section{Material and methods}

A 3 year old female Emu, weighing $40 \mathrm{~kg}$ (using digital weighing machine), was presented with a primary complaint of ingesting a large piece of barbed wire and anorexia since 2 weeks. Clinically, the proximal neck area was swollen and barbed wire was palpated, percutaneously. Dorso-ventral and lateral radiographs of the neck revealed a bunch of barbed wire in the cervical oesophageal region (Figure 1 \& Figure 2). Trachea was appreciable separately. As the bird was unable to eat anything, it was advised for emergency oesophagotomy under general anaesthesia.

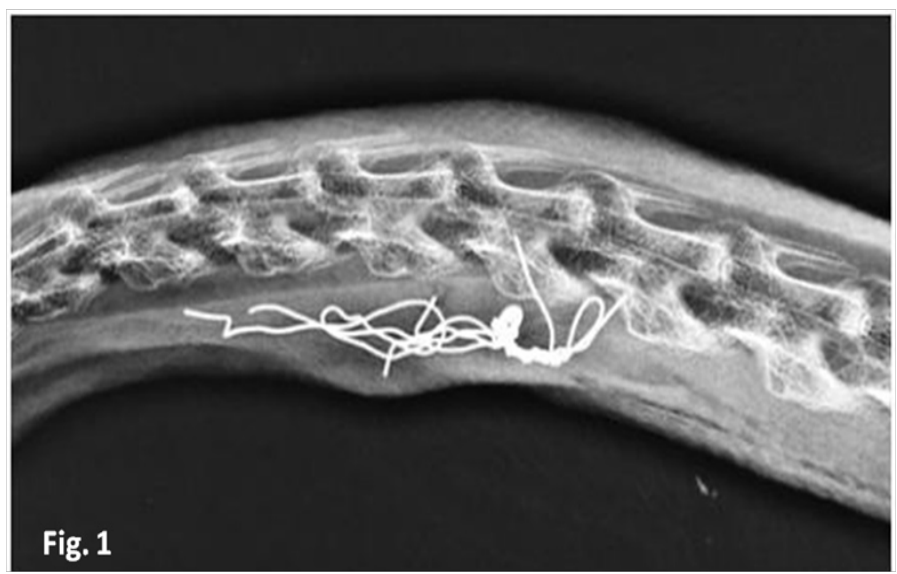

Figure I Lateral radiograph showing a bunch of metallic radio-opacities in the neck region.

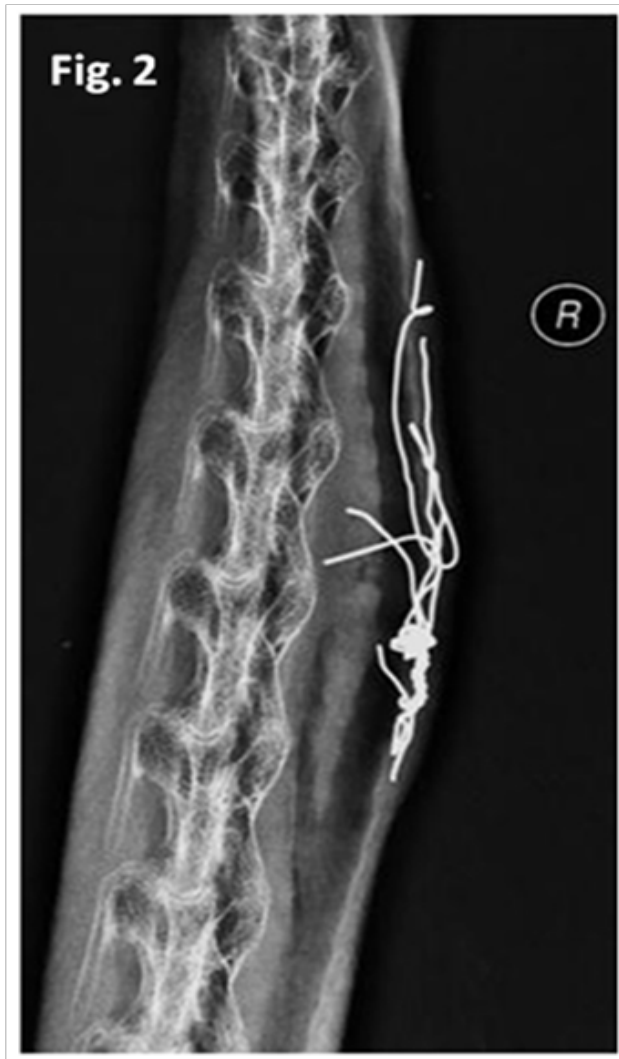

Figure 2 Dorso-ventral radiograph showing a bunch of metallic radioopacities on the right side of the neck region.

\section{Surgical treatment and result}

General anaesthesia was induced using Inj. xylazine $2 \mathrm{mg} / \mathrm{kg}$ and inj. ketamine $10 \mathrm{mg} / \mathrm{kg}$ combination, intramuscularly, in the thigh muscles. Anaesthesia was maintained using isoflurane mixed with oxygen using non-rebreathing circuit. The bird was restrained in lateral recumbency and surgical site was prepared by plucking 
feathers followed by scrubbing with antiseptic solution. Intravenous administration of Ringer's lactate solution was started and a warm body temperature was maintained. A longitudinal incision starting slightly cranial to the foreign body to the middle of the foreign body was given on the right side of the neck. The oesophagus was isolated and incised longitudinally to remove wire with the help of forceps. Oesophagus was sutured using Vicryl 3-0 in simple continuous pattern not involving the mucosa. A layer of subcuticular sutures was also applied. The skin was closed using nylon sutures in simple interrupted manner. The bird showed head up in nearly 20 minutes after disconnecting inhalation anesthesia. Inj. enrofloxacin $10 \mathrm{mg} / \mathrm{kg}$ and inj. meloxicam $0.2 \mathrm{mg} / \mathrm{kg}$ were administered. However, the bird died within 24 hours after operation.

\section{Discussion}

Environmental stress has been reported to be associated with ingestion of unusual foreign bodies in birds ${ }^{4}$ which may get lodged in the oesophagus, crop, proventriculus or ventriculus or in the intestines. ${ }^{5}$ Cited literature report ingestion and lodgment of various types of foreign bodies in the esophagus in birds like myna, ${ }^{6}$ goose $^{2}$ and Parakeet. ${ }^{7}$ Recent report by Shiju et al., ${ }^{3}$ reported surgical removal of a branch of Bambusa vulgaris lodged in the oesophgaus of an emu. As per the author's knowledge, there is lack of report on lodgment of metallic foreign body in the oesophagus causing obstruction in an Emu. Emu have the natural habit of ingestion of pebbles-up to 1.6 ounces which help to grind food in the gizzard. ${ }^{1}$ But the foreign body, in the present case, was a bunch of barbed wire, lodged in the oesophagus which has not been reported in the literature. The birds are always prone to surgical and anesthetic risks despite taking necessary precautions peri-operatively. In the present case report, the bird, died on the next postoperative day probably due to chronicity of the condition combined with anaesthetic or surgical stress.

\section{Conclusion}

This case report puts on record an incidence of a barbed wire as an oesophageal foreign body causing obstruction in an adult Emu. If presented early, the life of the bird could have been saved.

\section{Acknowledgements}

None.

\section{Conflicts of interest}

Author declares that there is no conflict of interest.

\section{References}

1. Patodkar VR, Rahane SD, Shejal MA, et al. Behaviour of Emu bird (Dromaius novaehollandiae). Vet World. 2009;2(11):439-440.

2. Saritas Z K, Pamuk K, Korkmaz M. et al. A case of Ventricular foreign body in a goose (Anser anser). J Anim Vet Adv. 2011;10 (8):991-992.

3. Shiju Simon M, Pazhanivel N. Oesophageal foreign body (Bambusa vulgaris) in an Emu. Indian Vet J. 2017;94(9):80-81.

4. Morishita TY, Aye PP, Harr BS. Crop impaction resulting from feather ball formation in caged layers. Avian Dis. 1999;43:160-163.

5. Wagner WM. Small intestinal foreign body in an adult electus parrot (Eclectus roratus). J South Afr Vet Med Assoc. 2005;76:46-48.

6. Hayati F, Lakzian A, Shariati E. et al. Surgical removal of a ventricular foreign body from a common myna (Acridotheres tristis): a case report. Vet Med. 2011;56(2):97-100.

7. Hayati F, Khafi MSA, Salmanzadeh N. et al. Surgical Removal of a tubelike foreign body from an alexandrine Parakeet (Psittacula eupatria) using a Ventricular Approach: A Case Report. Global Vet. 2012;9(6):696699 . 